\title{
An Alternative Humans to Mars Approach: Reducing Mission Mass with Multiple Mars Flyby Trajectories and Minimal Capability Investments
}

\author{
Ryan J. Whitley* \\ NASA Johnson Space Center, Houston, TX, 77058 \\ Richard Jedrey ${ }^{\dagger}$ \\ -shape NASA Johnson Space Center, Houston, TX, 77058 \\ Damon Landau ${ }^{\ddagger}$ \\ Jet Propulsion Laboratory, Pasadena, CA, 91109 \\ Cesar Ocampo ${ }^{\S}$ \\ Odyssey Space Research, LLC, Houston, TX, 77058
}

\begin{abstract}
Mars flyby trajectories and Earth return trajectories have the potential to enable lowercost and sustainable human exploration of Mars. Flyby and return trajectories are true minimum energy paths with low to zero post-Earth departure maneuvers. By emplacing the large crew vehicles required for human transit on these paths, the total fuel cost can be reduced. The traditional full-up repeating Earth-Mars-Earth cycler concept requires significant infrastructure, but a Mars only flyby approach minimizes mission mass and maximizes opportunities to build-up missions in a stepwise manner. In this paper multiple strategies for sending a crew of 4 to Mars orbit and back are examined. With pre-emplaced assets in Mars orbit, a transit habitat and a minimally functional Mars taxi, a complete Mars mission can be accomplished in 3 SLS launches and 2 Mars Flyby's, including Orion. While some years are better than others, ample opportunities exist within a given 15-year Earth-Mars alignment cycle. Building up a mission cadence over time, this approach can translate to Mars surface access. Risk reduction, which is always a concern for human missions, is mitigated by the use of flybys with Earth return (some of which are true free returns) capability.
\end{abstract}

\section{Introduction}

TXPloration of Mars is widely viewed as the long-term goal of the human space program. ${ }^{1}$ While interim Eoals to move beyond the International Space Station (ISS) are hotly debated in both policy and technical forums, sending humans to Mars is always a centerpiece of a global exploration strategy. ${ }^{2}$ Along with the recognition that Mars is a key part of the long-term strategy comes a second realization: human exploration of Mars is not only difficult and risky it is expensive and represents a budget challenge for NASA and other spacefaring nations. ${ }^{3}$ Thus, it is become critical to understand how to bridge the gap between what has become a consensus target but has been also viewed as unachievable at current funding levels. Studies have shown that a stepwise buildup to human space exploration is a logical approach, as long there is relevant mission content embedded with each step. ${ }^{4}$ Also, a reference exists for the ultimate exploration strategy, called NASA's Mars Design Reference Architecture 5.0 (DRA 5.0), which includes information on a series of transportation options that exist within could be evolved from current technologies. ${ }^{5}$ The open questions

*Aerospace Engineer, Exploration Mission Planning Office, 2101 Nasa Pkwy, Houston, TX, 77058, AIAA Member.

${ }^{\dagger}$ Aerospace Engineer, Flight Mechanics and Trajectory Design Branch, 2101 Nasa Pkwy, Houston, TX, 77058, AIAA Member.

¥Planetary Mission Architect, Project Systems Engineering and Formulation, Pasadena, CA, 91109, AIAA Member.

$\S$ Dean of Engineering and Senior Engineer, Universidad Sergio Arboleda, Bogota, Colombia and Odyssey Space Research LLC, Houston, TX, 77058, AIAA Member 
revolve primarily around the build-up strategy to achieve the end goal espoused in DRA 5.0 and how this strategy informs the key choices that exist within the Mars exploration trade tree. This paper does not dispute the well understood Mars exploration option space and the need to establish a step-by-step path to exploration. Instead this paper entertains the idea of conducting a smaller scale, less infrastructure intensive mission that journeys to Mars orbit and back with minimal cost. If feasible, such a mission could help pave the way by testing key technologies needed for the mission that will land the first humans on the surface. This paper will also focus solely on the transportation to and from the Mars system.

Smaller scale missions to Mars have been proposed both by government entities and commercial enterprises to meet a need for more near-term approaches. ${ }^{6,7}$ In addition, NASA has been conducting a series of studies known as the Evolvable Mars Campaign, seeking to understand how to propel exploration from the proving ground to Mars. Current studies feature a cadence of missions to first reach Mars orbit and perhaps visit Phobos and Deimos. ${ }^{8,9,10,11}$ The Inspiration Mars Foundation provided an intriguing proposal for a government and commercial partnership that featured a single Mars fly-by that journeyed to Mars and back without stopping. ${ }^{7}$ In the end, the mission was deemed to be too detached from the Mars exploration strategy and as it requires a launch in either 2018 or 2021, assets are needed too early to implement. The other approaches being studied connect more soundly with a broader exploration vision, but have also been shown to require multiple SLS launches and significant infrastructure even for the first complete Mars mission.

A need exists to find opportunities for early missions to Mars that can be developed within the framework of the broader exploration strategy. This paper seeks to understand if one such possibility would be to take advantage of multiple flyby trajectories in the context of free return trajectories to conduct a Mars orbital mission. The use of multiple flybys expands the number of opportunities available and thus allows planning to coincide more seamlessly with infrastructure development timelines rather than fixed deadlines. The use of flybys does not in this instance require on-going Earth-Mars Cyclers as has been well researched by the community. ${ }^{12}$ Instead, the use of multiple flybys enables single mission scenarios and frees up the ability to stay in the Mars vicinity for a time that is commiserate with a desire to provide significant mission content for the crew. The general mission architecture has been explored in a previous paper. ${ }^{13}$ This paper seeks to assess the feasibility of this approach with existing elements and understand the investment required for new elements. A full Mars cycle of trajectory data will be investigated to understand the relative sustainability of the approach. In addition, the ability to infuse flyby trajectories and hyperbolic rendezvous into other Mars architectures is discussed.

\section{Earth to Mars Fly-by Trajectories}

\section{A. Full Cycle Database Development}

Finding optimal trajectories for the architectures espoused requires the use of advanced astrodynamics tools with specific parameters and constraints. To that end, a comprehensive search was conducted that gridded up all possible Earth and Mars encounter times with both outbound and inbound legs calculated independently. Filters on the data included maximum $V_{\infty}$ values and maximum flight times as shown in Figure 1. Figure 1a displays the specific strategy to translate a multi-dimensional search into a two-dimensional grid search. Each arc was a lambert fit which permitted rapid trajectory generation with multiple filter applications. In the end, thousands of trajectories were generated and sorted, resulting in the points represented by Figure 1b. The vast majority of the data points are Earth-to-Mars-to-Earth (EME) free return trajectories, but additional trajectories involving double flybys of Mars (EMME) and free returns with Venus either before (EVME) or after (EMVE) a Mars flyby were also found. In the end the EME trajectories formed the basis for the dual habitat architecture and the EMME trajectories formed the basis for the loiter habitat architecture.

\section{B. Hyperbolic Rendezvous Risk Mitigation}

A unique and untested feature of the architectures required in the use of free return trajectories is the application of hyperbolic rendezvous. ${ }^{14}$ To that end, a study was conducted to assess the risks associated with hyperbolic rendezvous and address them. ${ }^{15}$ These risks include missed burns which can lead to missing the ride home and early burn cutoffs. Additional traded features of the hyperbolic rendezvous include catch up time and hyperbolic flyby altitude. In the end, the biggest factor on the total cost to do a hyperbolic rendezvous is the energy $\left(V_{\infty}\right)$ associated with the flyby. The higher the energy level of the hyperbolic trajectory, the higher the propellant cost. Accounting for additional risks associated with burn execution 


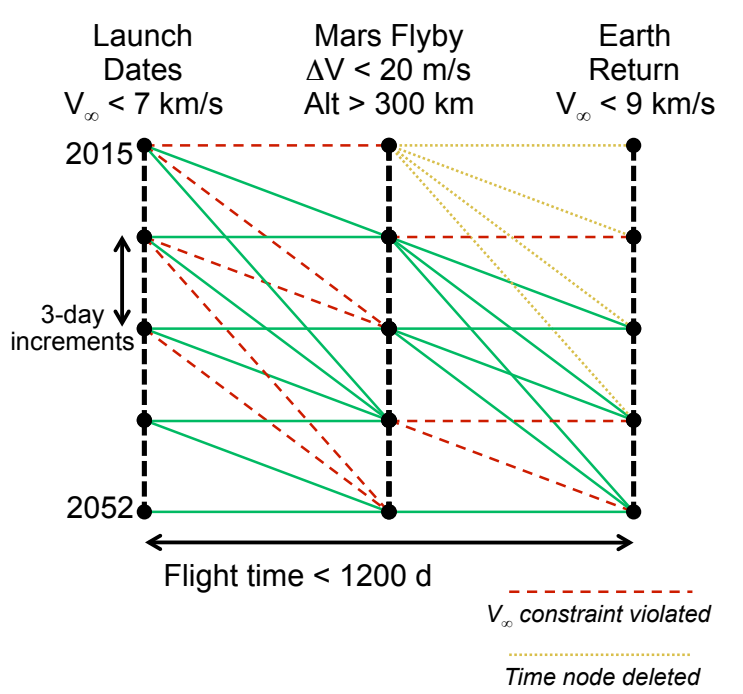

(a) Flyby Trajectory Search Strategy

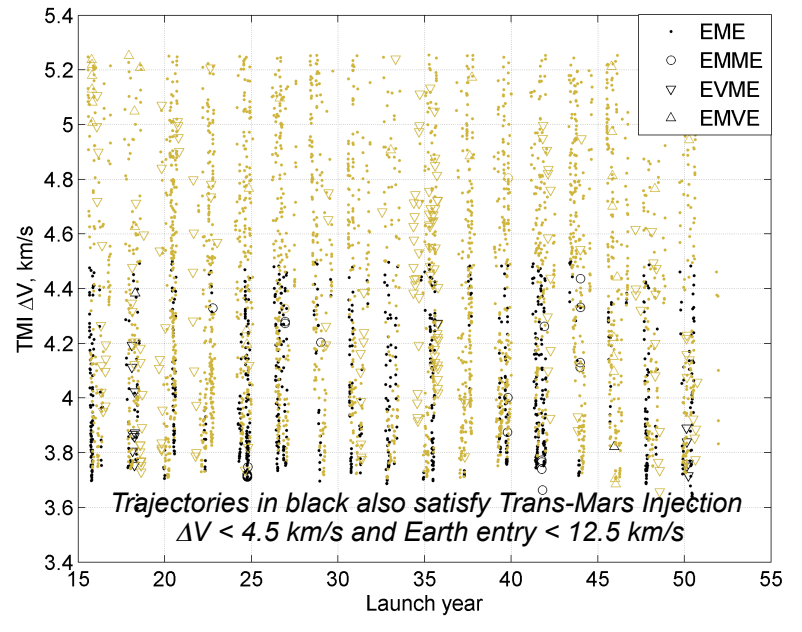

(b) Flyby Database By Year

Figure 1: Generating Mars Flyby and Free Return Trajectory Database

failure likewise increase the cost. In the end, the best way to mitigate the risk is to carry extra propellant to handle a reasonable set of off-nominal scenarios. The premier finding from the study suggests that when departing from a 1-day sol abort it likely less than $8 \%$ of the total $\Delta v$ to guarantee two opportunities in the form of two periapsis passes by setting the nominal departure to leave earlier than the optimal time. This amount of propellant may not be unreasonable for a given mission to hold in reserve if there is some margin in the design.

\section{Architecture Types}

While analyzing how to connect minimum energy Earth-Mars trajectory arcs to build mission scenarios, two approaches for Mars orbital access were discovered. As introduced previously, ${ }^{13}$ the Dual Habitat and Loiter Habitat architectures are uniquely suited as potential compromises between the well established Earth-Mars Cycler approach and the full-up direct insertion of all assets. A graphical representation of the trajectories and in-space elements is given in Figure 2. In addition to these approaches, a third architecture is used for comparison purposes and is called the Full-Up Habitat architecture.

In summary:

1. Dual Habitat Architecture: Two habitats depart independently and arrive at Mars 1 year apart. The crew transfers from the first habitat into a Mars orbit to begin a 1 year stay and then the crew transfers to the second habitat as it performs its flyby and returns to Earth 1 year later.

2. Loiter Habitat Architecture: A single (larger) habitat with crew aboard departs Earth and arrives about 1 year later at Mars. While the habitat does a Mars flyby, the crew transfers to orbit. As the same habitat does a second Mars flyby 1 year later, the crew transfers back to return to Earth.

3. Full-Up Habitat Architecture: A single habitat, similar in size to the loiter habitat, departs Earth with crew aboard and arrives about 1 year later at Mars. The entire habitat transfers with crew to Mars orbit. And then 1 year later, the crew in the original transit habitat transfers back to return to Earth.

While the architectural approaches have been outlined previously, the ability to conduct these missions within planned (Orion and SLS) and future (habitats and in-space stages) exploration capabilities has not yet been assessed. Thus, the architectures are translated into actual launch sequences given current designs for all vehicles. Orion and SLS capabilities are established based on externally available resources ${ }^{16}$ as well as on-going internal trades at NASA. The SLS con-ops and $C_{3}$ performance for the SLS Block 2B vehicle is given in Figure 3 and is used as the baseline performance limit for all architectures evaluated. 


\section{Dual Habitat}

Key Features:

1. 2 Fly-by Trajectories $=2$ one-year Habitats

2. Taxi loiters in Mars 1-sol between Transfers

3. All burns performed by zero boil off LOX/CH4 Stages

4. Additional Mars one-year habitat pre-deployed

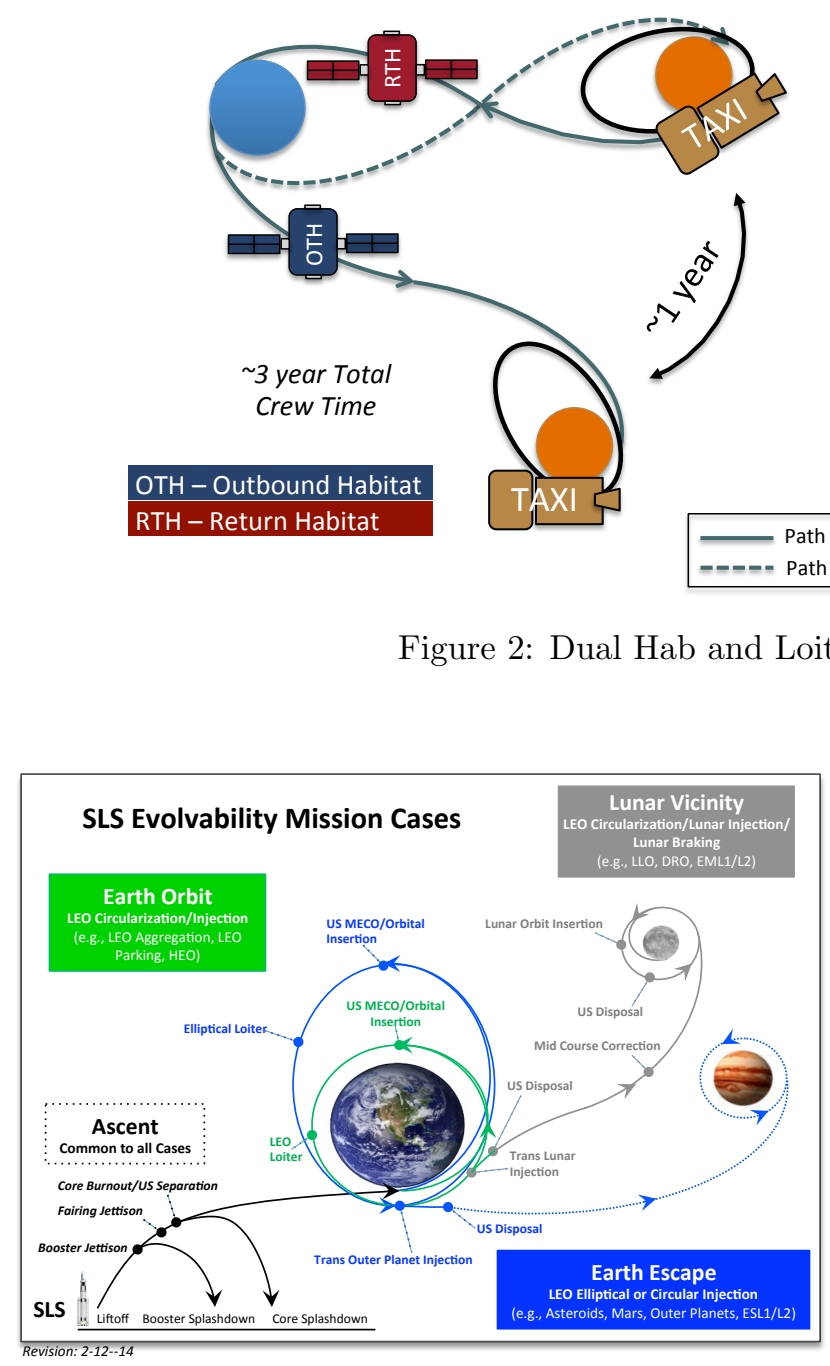

\section{Loiter Habitat}

\section{Key Features:}

1. 1 Fly-by Trajectory = 1 two-year Habitat

2. Taxi loiters in Mars 1-sol between Transfers

3. All burns performed by zero boil off LOX/CH4 Stages

4. Additional Mars one-year habitat pre-deployed

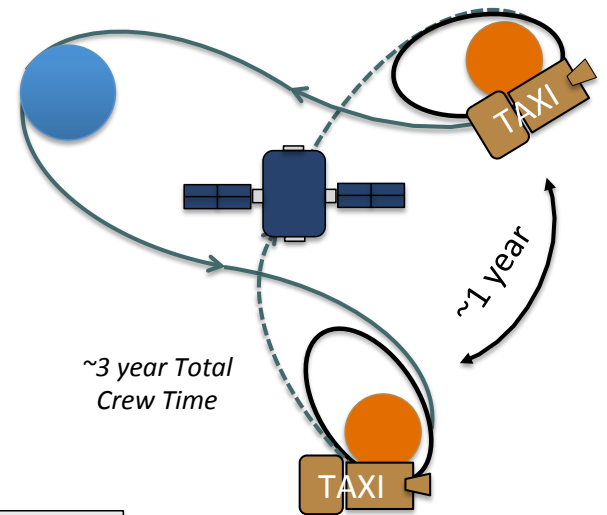

Path with Crew

Path without Crew

(a) SLS Conops

Figure 3: Performance Metrics for SLS Usage

\section{A. Dual Habitat Architecture}

The Dual Habitat architecture features two habitats which depart on independent trajectory arcs. The crew departs on the outbound transit habitat $(\mathrm{OTH})$ and subsequently transfers to Mars orbit via a 10 day capable taxi vehicle. Then after staying in a pre-emplaced habitat the same Mars taxi transfers back to the return transit habitat (RTH). In order to maintain feed forward applicability to Mars architectures a Mars 1-sol was used as the baseline Mars operating orbit but other orbits could be equally viable depending on the mission objectives.

Given the expected capability of the SLS Block2B vehicle, the number of launches to enable this architecture is at minimum 3 launches plus 1 for pre-emplaced orbital assets. In addition, SLS currently anticipates 
a flight rate for SLS of 3 per year, which constrains the expected sequence of flights. The flow of con-ops is given in Figure 4 and meets the 3 launch per year cadence for SLS.

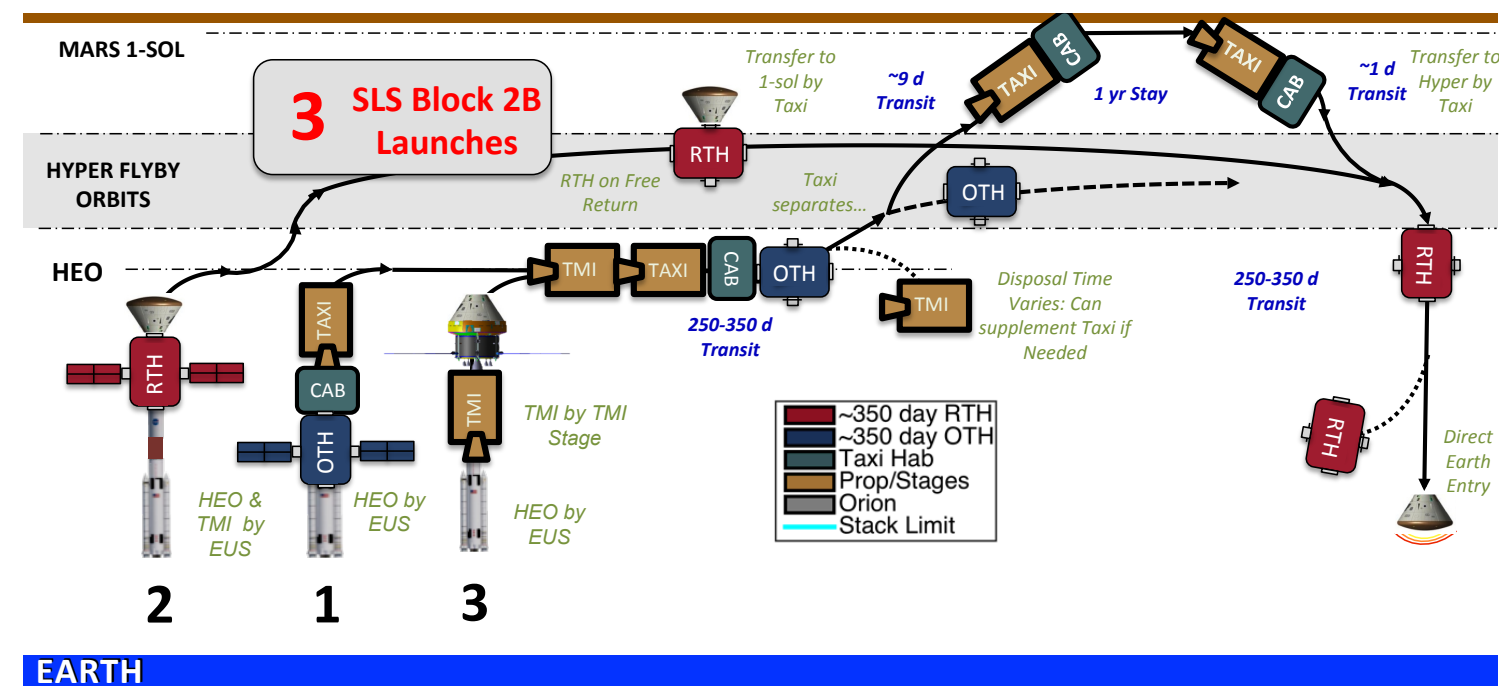

Figure 4: Dual Habitat Concept of Operations

The order of launches is enumerated in Figure 4 below each SLS icon. The first launch (middle icon) contains the outbound transit habitat $(\mathrm{OTH})$ and taxi vehicle without crew aboard. The target orbit for Mars aggregation and departure for SLS is $400 \times 200,000 \mathrm{~km}$, a large HEO where it will rendezvous with the third SLS launch containing the crew and a liquid oxygen / liquid methane in-space propulsion stage. As a result of the expected SLS launch rate, the OTH and taxi vehicle must linger in quiescent mode in HEO for a year. As these vehicles are designed for long duration with mass margin, it is anticipated that as the vehicles will require minimal depletion of consumables and will be monitored remotely so that if any repairs are necessary the third and final launch with crew will provide an opportunity to bring spares and other repair equipment. Meanwhile, the return habitat launches 6 months later on its trajectory arc to Mars. The trajectory can be shaped optimally as needed as the RTH and crew entry capsule (Orion) need not rendezvous with any other assets before departing.

The crewed portion of the mission begins approximately a year after the first launch when the crew inserts into HEO with the Trans Mars Injection (TMI) stage, completes rendezvous with the OTH, and after an adequate checkout period, departs for Mars. After this TMI burn completes, the crew is committed to going to Mars and must insert into Mars orbit and also catch the RTH for the ride back. The first maneuver takes the crew in the 10-day taxi to the Mars 1-sol abort. This maneuver aligns the plane of the 1-sol orbit with the departure hyperbola associated with the RTH and thus requires an optimal multi-burn transfer. Then after approximately a one year stay in orbit, the taxi is then re-initialized for transit to the RTH. These two critical sequences elevates the risk of this mission as the architecture would only be favorable if the propellant costs are minimized which would preclude excessive propellant loads required to abort from this sequence of burns. Table 1 provides a set of optimal launch and trajectory parameters associated with a Earth to Mars cycle spanning from 2024 to 2041. An examination of the data in the table reveals that there can be a wide variation in taxi $\Delta v$ costs. In general, the cost to insert into 1-sol orbit is greater than the departure cost, in some years eclipsing the $3 \mathrm{~km} / \mathrm{s}$ mark. The ability to close the mission in 3 launches for each epoch is given in the results section. 
Table 1: Dual Habitat Trajectory Table

\begin{tabular}{|c|c|c|c|c|c|c|c|c|c|}
\hline & & \multicolumn{2}{|c|}{ Earth Departure } & \multicolumn{2}{|c|}{ Mars Arrival } & \multicolumn{2}{|c|}{ Mars Departure } & \multicolumn{2}{|c|}{ Earth Entry } \\
\hline Year & Launch & Date & $c_{3}{ }^{a}$ & Date & $\Delta v^{b}$ & Date & $\Delta v^{b}$ & Date & Entry Speed $^{b}$ \\
\hline \multirow{3}{*}{2024} & 1-OTH & $\sim 10 / 2023$ & - & - & - & - & - & - & \\
\hline & 2-RTH & $5 / 31 / 24$ & 15.0 & - & - & $10 / 20 / 26$ & .81 & $5 / 14 / 27$ & 11.9 \\
\hline & 3-Crew & $10 / 2 / 24$ & 11.2 & $8 / 31 / 25$ & 2.28 & - & - & - & - \\
\hline \multirow{3}{*}{2026} & 1-OTH & $\sim 11 / 2026$ & - & - & - & - & - & - & \\
\hline & 2-RTH & $7 / 20 / 26$ & 13.0 & - & - & $8 / 9 / 28$ & .86 & $7 / 6 / 29$ & 11.7 \\
\hline & 3-Crew & $10 / 31 / 26$ & 9.3 & $9 / 6 / 27$ & 1.17 & - & - & - & - \\
\hline \multirow{3}{*}{2029} & 1-OTH & $\sim 11 / 2027$ & - & - & - & - & - & - & \\
\hline & 2-RTH & $9 / 26 / 28$ & 22.7 & - & - & $12 / 9 / 30$ & 1.06 & $9 / 23 / 31$ & 12.5 \\
\hline & 3-Crew & $11 / 23 / 28$ & 9.1 & $9 / 19 / 29$ & 1.11 & - & - & - & - \\
\hline \multirow{3}{*}{2031} & 1-OTH & $\sim 12 / 2029$ & - & - & - & - & - & - & \\
\hline & 2-RTH & $10 / 19 / 30$ & 19.5 & - & - & $12 / 26 / 32$ & 1.36 & $10 / 8 / 33$ & 12.3 \\
\hline & 3-Crew & $12 / 28 / 30$ & 10.4 & $10 / 8 / 31$ & 1.31 & - & - & - & - \\
\hline \multirow{3}{*}{2033} & 1-OTH & $\sim 4 / 2032$ & - & - & - & - & - & - & \\
\hline & 2-RTH & $10 / 9 / 32$ & 17.5 & - & - & $1 / 1 / 35$ & 1.91 & $11 / 3 / 35$ & 11.7 \\
\hline & 3-Crew & $4 / 16 / 33$ & 7.7 & $1 / 27 / 34$ & 1.87 & - & - & - & - \\
\hline \multirow{3}{*}{2035} & 1-OTH & $\sim 6 / 2034$ & - & - & - & - & - & - & \\
\hline & 2-RTH & $11 / 8 / 34$ & 11.2 & - & - & $11 / 27 / 36$ & .89 & $10 / 5 / 37$ & 12.0 \\
\hline & 3-Crew & $6 / 27 / 35$ & 10.4 & $1 / 14 / 36$ & 3.27 & - & - & - & - \\
\hline \multirow{3}{*}{2037} & 1-OTH & $\sim 8 / 2036$ & - & - & - & - & - & - & \\
\hline & 2-RTH & $4 / 22 / 37$ & 12.0 & - & - & $10 / 29 / 39$ & .97 & $6 / 14 / 40$ & 12.5 \\
\hline & 3-Crew & $8 / 18 / 37$ & 16.4 & $8 / 4 / 38$ & 3.98 & - & - & - & - \\
\hline \multirow{3}{*}{2039} & 1-OTH & $\sim 9 / 2038$ & - & - & - & - & - & - & \\
\hline & 2-RTH & $5 / 27 / 39$ & 14.3 & - & - & $11 / 2 / 41$ & .82 & $7 / 20 / 42$ & 12.5 \\
\hline & 3-Crew & $9 / 20 / 39$ & 12.5 & $8 / 26 / 40$ & 2.67 & - & - & - & - \\
\hline \multirow{3}{*}{2041} & 1-OTH & $\sim 10 / 2040$ & - & - & - & - & - & - & \\
\hline & 2-RTH & $6 / 4 / 41$ & 17.3 & - & - & $9 / 29 / 43$ & .82 & $7 / 14 / 44$ & 12.0 \\
\hline & 3-Crew & $10 / 21 / 41$ & 9.7 & $9 / 4 / 42$ & 1.70 & - & - & - & - \\
\hline
\end{tabular}

${ }^{a} c_{3}$ units are $\mathrm{km}^{2} / \mathrm{s}^{2}$

${ }^{b} \Delta v$ and Entry Speed units are $\mathrm{km} / \mathrm{s}$

\section{B. Loiter Habitat Architecture}

The Loiter Habitat architecture features a single and much larger habitat which departs on a single Earth to Mars to Mars again to Earth trajectory arc. As not every opportunity in the two year Earth-Mars cycle is purely ballistic, the crewed vehicle may at times need to perform correction maneuvers to maintain the double Mars flyby path. Upon Mars arrival, the crew transfers to Mars orbit via a 10 day capable taxi vehicle. Then after staying in a pre-emplaced habitat, the same Mars taxi transfers the crew back to the original loiter habitat. The use of taxis in accomplished in the same way that the transfers are conducted for the Dual Habitat architecture using hyperbolic rendezvous. Likewise the Mars 1-sol orbit was the baseline and the first taxi transfer aligns the orbit plane of the 1-sol orbit to minimize plane change to the departure hyperbola associated with the second flyby.

In the case of the Loiter Habitat architecture, the SLS Block2B vehicle permits a minimum of 2 launches to plus 1 for pre-emplaced orbital assets. With the SLS flight rate of SLS of 3 per year, an approximately 6 month delay is used to constrain the 2 launch aggregation. The flow of con-ops is given in Figure 5, easily accomplished within the 3 launch per year SLS launch cadence.

With only two launches required for the crewed portion of the mission, the first launch maximizes payload delivered to HEO orbit with the crew launched second with any required in-space propulsion stage payloads as shown in Figure 5. The target orbit for Mars aggregation is gain a large departure HEO of $400 \times 200,000$ $\mathrm{km}$. The habitat and taxi vehicle will likely have to linger for up to 6 months in quiescent mode in HEO as opposed to 1 year for the dual habitat approach. The crew then inserts into HEO with the TMI stage prior to the departure epoch as necessary to complete rendezvous and checkout. After the TMI burn is completed, 


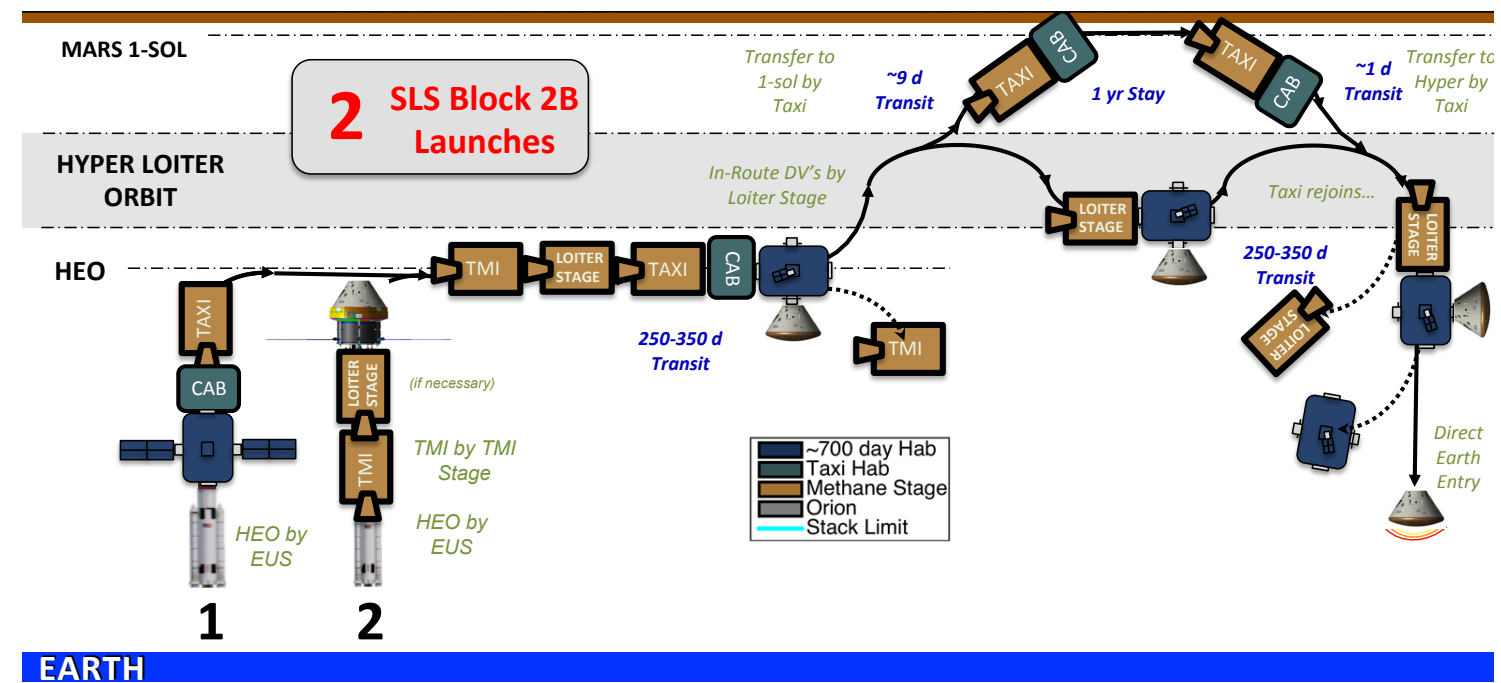

Figure 5: Loiter Habitat Concept of Operations

Table 2: Loiter Habitat Trajectory Table

\begin{tabular}{ccccccccccc}
\hline \hline & & \multicolumn{1}{c}{ Earth Departure } & \multicolumn{2}{c}{ Enroute } & \multicolumn{2}{c}{ Taxi } & \multicolumn{2}{c}{ Earth Entry } \\
\hline Year & Launch & Leg & Date & $c_{3}{ }^{a}$ & Date & $\Delta v^{b}$ & Date & $\Delta v^{b}$ & Date & Entry Speed $^{b}$ \\
\hline \multirow{2}{*}{2024} & 1-Hab & To HEO & $\sim 4 / 2024$ & - & - & - & - & - & - & \\
& 2-Crew & E-M & $10 / 5 / 24$ & 13.4 & - & - & $9 / 18 / 25$ & 1.09 & - & - \\
& 2-Crew & M-E & - & - & - & - & $7 / 20 / 26$ & 1.01 & $6 / 8 / 27$ & 11.5 \\
\hline \multirow{2}{*}{2026} & 1-Hab & To HEO & $\sim 5 / 2026$ & - & - & - & - & - & - & \\
& 2-Crew & E-M & $11 / 27 / 26$ & 16 & $5 / 8 / 27$ & .126 & $9 / 3 / 27$ & 1.28 & - & - \\
& 2-Crew & M-E & - & - & - & - & $7 / 2 / 28$ & 1.13 & $6 / 25 / 29$ & 11.6 \\
\hline \multirow{2}{*}{2029} & 1-Hab & To HEO & $\sim 6 / 2028$ & - & - & - & - & - & - & \\
& 2-Crew & E-M & $12 / 29 / 28$ & 16 & $4 / 21 / 29$ & .205 & $9 / 7 / 29$ & 1.74 & - & - \\
& 2-Crew & M-E & - & - & - & - & $7 / 9 / 30$ & 1.32 & $7 / 19 / 31$ & 12.0 \\
\hline \multirow{2}{*}{2031} & 1-Hab & To HEO & $\sim 8 / 2030$ & - & - & - & - & - & - & \\
& 2-Crew & E-M & $2 / 13 / 31$ & 16 & $9 / 15 / 31$ & .315 & $9 / 24 / 31$ & 1.78 & - & - \\
& 2-Crew & M-E & - & - & $1 / 1 / 33$ & .201 & $8 / 10 / 32$ & 1.20 & $8 / 25 / 33$ & 11.9 \\
\hline \multirow{2}{*}{2033} & 1-Hab & To HEO & $\sim 9 / 2032$ & - & - & - & - & - & - & \\
& 2-Crew & E-M & $3 / 31 / 33$ & 16 & $10 / 13 / 33$ & .136 & $11 / 4 / 33$ & 1.72 & - & - \\
& 2-Crew & M-E & - & - & $2 / 25 / 35$ & .964 & $10 / 28 / 34$ & 1.19 & $10 / 9 / 35$ & 11.9 \\
\hline \multirow{2}{*}{2035} & 1-Hab & To HEO & $\sim 1 / 2035$ & - & - & - & - & - & - & \\
& 2-Crew & E-M & $7 / 22 / 35$ & 16 & $1 / 23 / 36$ & .521 & $7 / 20 / 36$ & 1.37 & - & - \\
& 2-Crew & M-E & - & - & $8 / 10 / 37$ & .334 & $7 / 1 / 37$ & 1.53 & $1 / 30 / 38$ & 11.7 \\
\hline \multirow{2}{*}{2037} & 1-Hab & To HEO & $\sim 3 / 2037$ & - & - & - & - & - & - & \\
& 2-Crew & E-M & $9 / 10 / 37$ & 16 & - & - & $9 / 15 / 38$ & 1.41 & - & - \\
& 2-Crew & M-E & - & - & $8 / 26 / 39$ & .195 & $7 / 29 / 39$ & 1.44 & $3 / 19 / 40$ & 11.8 \\
\hline \multirow{2}{*}{2039} & 1-Hab & To HEO & $\sim 4 / 2039$ & - & - & - & - & - & - & \\
& 2-Crew & E-M & $10 / 3 / 39$ & 12.0 & - & - & $10 / 4 / 40$ & 1.24 & - & - \\
& 2-Crew & M-E & - & - & - & - & $8 / 5 / 41$ & 1.07 & $4 / 29 / 42$ & 11.8 \\
\hline \multirow{2}{*}{2041} & 1-Hab & To HEO & $\sim 4 / 2041$ & - & - & - & - & - & - & \\
& 2-Crew & E-M & $10 / 21 / 41$ & 10 & - & - & $9 / 27 / 42$ & 1.13 & - & - \\
& 2-Crew & M-E & - & - & - & - & $7 / 26 / 43$ & .92 & $6 / 28 / 44$ & 11.6 \\
\hline
\end{tabular}

${ }^{a} c_{3}$ units are $\mathrm{km}^{2} / \mathrm{s}^{2}$

${ }^{b} \Delta v$ and Entry Speed units are $\mathrm{km} / \mathrm{s}$ 
the crew is committed to going to Mars and must insert either into Mars orbit or remain in the loiter habitat as it leaves Mars to return 1 year later for a second Mars passage and return to Earth. The use of the EMME free return trajectory does allow for the crew to remain on the habitat for the entire 3 year journey in case an emergency prevented insertion into Mars orbit, assuming enough consumables remain to survive. The same procedure as dual habitat is followed, with a multi-burn transfer via the 10-day taxi to the Mars 1-sol orbit and back again to the habitat. Hyperbolic rendezvous is again required for both maneuvers. Table 2 provides a set of optimal trajectory parameters with the same Earth to Mars cycle spanning the 15 year period from 2024 to 2041. Using the values from Table 2, the loiter habitat architecture is evaluated in its ability to close the mission in 2 launches in the results section.

\section{Full-Up Habitat Architecture}

The Full-Up Habitat architecture, as a comparison to the fly-by based habitat architectures, utilizes a single habitat but is not constrained to do a free return or be close to a free return. Instead, the overall impulsive maneuver cost is minimized within a given conjunction class mission. There is no taxi vehicle in this architecture. Instead multiple liquid oxygen / methane stages are lofted to HEO and then are burned and dropped off as they are depleted. To offer the most accurate comparison, the Mars 1-sol orbit was used again as the baseline. The Full-Up Habitat architecture is generated primarily for comparison purposes and most closely resembles another minimal Mars transportation infrastructure approach already conceived in more detail although there are a few significant differences. ${ }^{6}$

Similarly to the Dual Habitat architecture, the SLS Block2B vehicle will require a minimum of 3 launches to send the crew to Mars plus at least 1 for pre-emplaced orbital assets for the orbit stay. The 3 SLS launches can be spread as desired along the year prior to Mars departure. The flow of con-ops is given in Figure 6, with all 3 launches required.

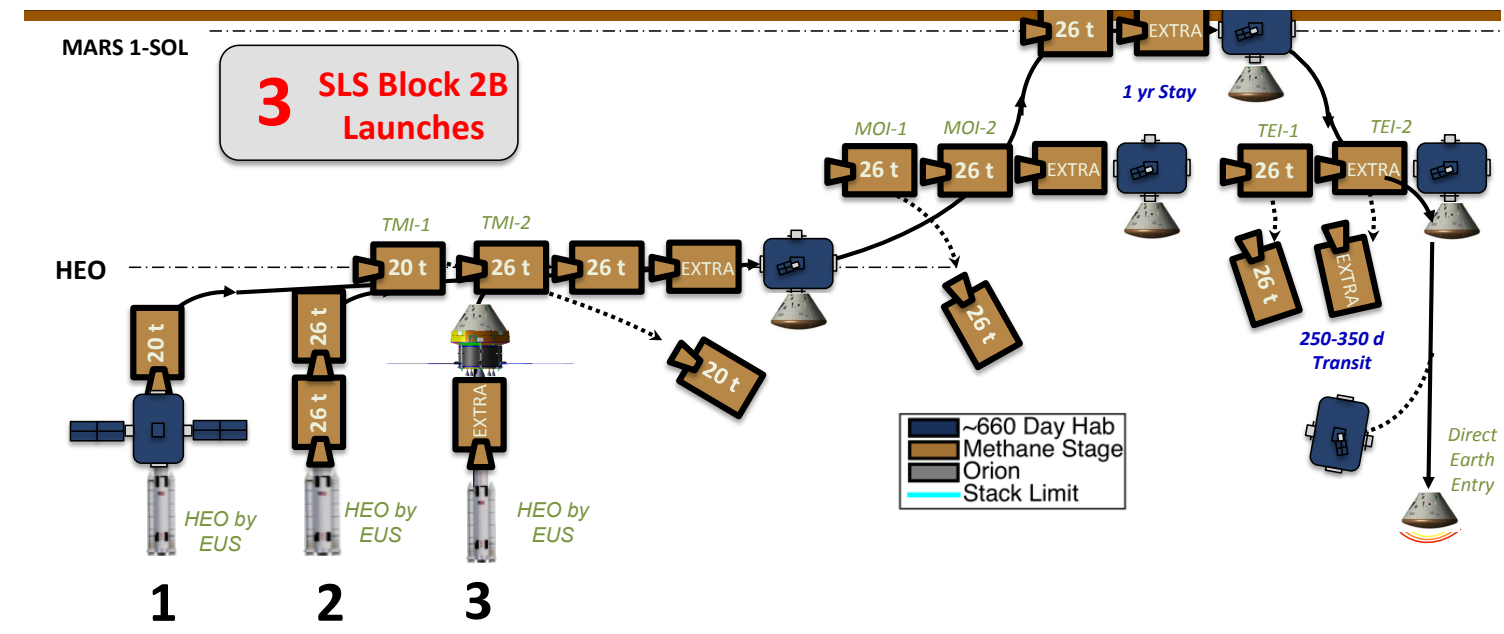

EARTH

Figure 6: Full-Up Habitat Concept of Operations

The mission was designed to maximize payload capacity so in-space propulsion stages were designed for launches 1 and 2 with fixed sizes of $20 \mathrm{t}$ and $26 \mathrm{t}$ respectively. The crew would then take a smaller stage with it if necessary. While the con-ops in Figure 6 gives distinct times for stage disposal, the epoch dependencies were allowed to fluctuate and the stage was simply disposed when propellant for a given stage was fully depleted. Similar to the Dual Habitat architecture concept, the 3 launches for the Full-Up Habitat architecture are spread over 1 year as shown in Table 3. The combined stack then must perform the maneuvers as given in the final row of every two year opportunity. 
Table 3: Full-Up Habitat Trajectory Table

\begin{tabular}{|c|c|c|c|c|c|c|c|c|c|}
\hline \multirow[b]{2}{*}{ Year } & \multirow[b]{2}{*}{ Launch } & \multicolumn{2}{|c|}{ Earth Departure } & \multicolumn{2}{|c|}{ Mars Arrival } & \multicolumn{2}{|c|}{ Mars Departure } & \multicolumn{2}{|c|}{ Earth Entry } \\
\hline & & Date & $c_{3}{ }^{a}$ & Date & $\Delta v^{b}$ & Date & $\Delta v^{b}$ & Date & Entry Speed $^{b}$ \\
\hline \multirow{3}{*}{2024} & 1-Hab & $\sim 10 / 2023$ & - & - & - & - & - & - & - \\
\hline & 2-Stages & $\sim 4 / 2024$ & - & - & - & - & - & - & - \\
\hline & 3-Crew & $10 / 1 / 24$ & 11.3 & $8 / 27 / 25$ & .78 & $8 / 2 / 26$ & .93 & $6 / 18 / 27$ & 11.5 \\
\hline \multirow{3}{*}{2026} & 1-Hab & $\sim 10 / 2023$ & - & - & - & - & - & - & - \\
\hline & 2-Stages & $\sim 4 / 2024$ & - & - & - & - & - & - & - \\
\hline & 3-Crew & $10 / 31 / 26$ & 9.3 & $9 / 6 / 27$ & .59 & $8 / 11 / 28$ & .96 & $7 / 17 / 29$ & 11.6 \\
\hline \multirow{3}{*}{2029} & 1-Hab & $\sim 10 / 2023$ & - & - & - & - & - & - & - \\
\hline & 2-Stages & $\sim 4 / 2024$ & - & - & - & - & - & - & - \\
\hline & 3-Crew & $11 / 29 / 28$ & 9.2 & $9 / 25 / 29$ & .62 & $12 / 9 / 30$ & .99 & $10 / 5 / 31$ & 12.6 \\
\hline \multirow{3}{*}{2031} & 1-Hab & $\sim 10 / 2023$ & - & - & - & - & - & - & - \\
\hline & 2-Stages & $\sim 4 / 2024$ & - & - & - & - & - & - & - \\
\hline & 3-Crew & $12 / 29 / 30$ & 10.6 & $10 / 5 / 31$ & .71 & $1 / 27 / 33$ & .92 & $9 / 4 / 33$ & 11.8 \\
\hline \multirow{3}{*}{2033} & 1-Hab & $\sim 10 / 2023$ & - & - & - & - & - & - & - \\
\hline & 2-Stages & $\sim 4 / 2024$ & - & - & - & - & - & - & - \\
\hline & 3 -Crew & $4 / 17 / 33$ & 9.1 & $11 / 3 / 33$ & .75 & $5 / 7 / 35$ & 1.2 & $11 / 23 / 35$ & 11.5 \\
\hline \multirow{3}{*}{2035} & 1-Hab & $\sim 10 / 2023$ & - & - & - & - & - & - & - \\
\hline & 2-Stages & $\sim 4 / 2024$ & - & - & - & - & - & - & - \\
\hline & 3-Crew & $6 / 26 / 35$ & 10.3 & $1 / 12 / 36$ & .77 & $7 / 5 / 37$ & 1.38 & $4 / 1 / 38$ & 11.6 \\
\hline \multirow{3}{*}{2037} & 1-Hab & $\sim 10 / 2023$ & - & - & - & - & - & - & - \\
\hline & 2-Stages & $\sim 4 / 2024$ & - & - & - & - & - & - & - \\
\hline & 3-Crew & $8 / 14 / 37$ & 17.0 & $7 / 30 / 38$ & 1.1 & $7 / 25 / 39$ & 1.33 & $4 / 30 / 40$ & 11.5 \\
\hline \multirow{3}{*}{2039} & 1-Hab & $\sim 10 / 2023$ & - & - & - & - & - & - & - \\
\hline & 2-Stages & $\sim 4 / 2024$ & - & - & - & - & - & - & - \\
\hline & 3-Crew & $9 / 23 / 39$ & 12.5 & $8 / 28 / 40$ & .84 & $7 / 24 / 41$ & .98 & $5 / 20 / 42$ & 11.5 \\
\hline \multirow{3}{*}{2041} & 1-Hab & $\sim 10 / 2023$ & - & - & - & - & - & - & - \\
\hline & 2-Stages & $\sim 4 / 2024$ & - & - & - & - & - & - & - \\
\hline & 3-Crew & $10 / 22 / 41$ & 9.8 & $9 / 7 / 42$ & .64 & $8 / 23 / 43$ & .88 & $7 / 28 / 44$ & 11.8 \\
\hline
\end{tabular}

${ }^{a} c_{3}$ units are $\mathrm{km}^{2} / \mathrm{s}^{2}$

${ }^{b} \Delta v$ and Entry Speed units are $\mathrm{km} / \mathrm{s}$

\section{Minimal Capability Investments}

In order to truly evolve an architecture to enable early missions to Mars, a step-wise investment in new capabilities will be key. If elements built for operation in the cis-lunar proving ground are focused on a few specific new developments it may be enough to send the first crew to Mars orbit and back. There are some aspects of any long duration mission to Mars (or deep space in general) that are unavoidable. The crew must survive a multi-year mission with reliable habitation and some type of in-space propulsion must be developed, either from a range of investment strategies into proposed or existing technology or from low TRL options. To enable the architecture given here with fewest number of launch vehicles, two other developments must be made, but both needs would cost much less than the first two developments. In addition, these new capabilities feed forward directly to what is needed for future Mars surface missions. These four investments can be summarized as follows:

1. Deep Space Habitat: The shortest mission to Mars and back ever proposed was a free return flyby of about 500 days. ${ }^{7}$ The dual habitat concept allows this duration to be split into two habitat pieces, approaching a time of about 300 days each way at a minimum. Most missions are closer to 1000 days total. Nothing that can survive the deep space environment for this amount of time is ready or available, even with ISS experience applied directly to a new habitat today. This would be the biggest new development and the challenges of obtaining this capability have been well documented. ${ }^{17,18}$

2. $\mathrm{LOX} / \mathrm{CH}_{4}$ In-Space Stage: There are several different options for in-space propulsion. Most transportation architectures require a large investment in new propulsion technologies such as high-powered 
solar electric propulsion, nuclear thermal propulsion or nuclear electric propulsion. As the use of flybys has minimized the transfer costs, these low TRL options can be avoided and instead a chemical propulsion stage using liquid oxygen and methane would be developed. The engine technology is already being tested and the gaps remaining are well understood. ${ }^{19}$

3. 10 day Taxi Cab: The taxi vehicle in the flyby architectures must keep the crew alive for a very short period of time, about 10 days, and thus can be a very small element. As development costs relate very strongly with spacecraft size, and the duration of the vehicle is well within current in-space technologies, this development effort would be much smaller than the deep space habitat. In addition, the taxi cab function could be used as the basis for other elements including the Mars Ascent Vehicle (MAV) cabin. ${ }^{20}$

4. Orion Heat Shield Upgrade: The Orion vehicle currently has the capability to handle lunar return speeds up to $11 \mathrm{~km} / \mathrm{s}$. As Earth entry speeds were limited to be less than $12.5 \mathrm{~km} / \mathrm{s}$, the upgrade should have a minimal impact to overall mass as validation of the heat shield will have occurred in prior missions.

The elements and the assumptions regarding their range of performance is given in Table 4 .

Table 4: Element Characteristics Table

\begin{tabular}{cccccccc}
\hline \hline & \multicolumn{2}{c}{ Habitat } & \multicolumn{2}{c}{ In-Space Stage } & Taxi Cab & \multicolumn{2}{c}{ Orion } \\
\hline Parameter & Min & Max & Min & Max & Nominal & CM & SM Dry \\
\hline Mass & $26.2 \mathrm{t}$ & $38.6 \mathrm{t}$ & $\sim 3 \mathrm{t}$ & $\sim 30 \mathrm{t}$ & $3 \mathrm{t}$ & $10.4 \mathrm{t}$ & $6.8 \mathrm{t}$ \\
Duration & $\sim 350 \mathrm{~d}$ & $\sim 1000 \mathrm{~d}$ & - & - & $10 \mathrm{~d}$ & $21 \mathrm{~d}$ & $21 \mathrm{~d}$ \\
Number of Crew & 4 & 4 & - & - & 4 & 4 & 4 \\
PMF & - & - & 0.6 & 0.75 & - & - & 0.56 \\
Isp & - & - & $355 \mathrm{~s}$ & $355 \mathrm{~s}$ & - & - & $315 \mathrm{~s}$ \\
\hline \hline
\end{tabular}

\section{Number of Launches Required}

As alluded to in the discussion of the different architectures, the number of launches is dependent on the total $\Delta v^{\prime} s$ required as well as the masses of the different elements pushed around on the various trajectory arcs. The minimum number of launches for the transportation only portion of the crew missions is 3 for Dual Habitat, 2 for Loiter Habitat and 3 for Full-Up Habitat architectures. However, not every synodic opportunity is equal as shown in Tables 1, 2, and 3. Thus, the ability to successfully meet the minimum launch requirements varies. The performance variability can be seen in Figure 7.

For the Dual Habitat architecture 5 out of 9 (or about 55\%) of the opportunities fit within the 3 launch manifest as shown in Figure 7a. Of the synodic cycle years that fail to close, 2 (2029 and 2041) violate due to the energy requirements to depart on a single launch with the RTH. These trajectories have $C_{3}$ values exceeding $16 \mathrm{~km}^{2} / \mathrm{s}^{2}$. A possible way to make these years feasible would be to force the trajectory arcs designed for the RTH to be lower energy. The remaining violators (2035 and 2039) are outliers in respect to the $\Delta v$ requirements for insertion into Mars 1-sol with both transfers exceeding $3 \mathrm{~km} / \mathrm{s}$ as shown in Table 1.

For the Loiter Habitat architecture 6 out of 9 (or about $67 \%$ ) of the opportunities fit within the 2 launch manifest as shown in Figure 7b. Note if the Loiter Habitat Architecture was spread over 3 launches, all epochs would be feasible or $100 \%$ of the opportunities could be flown with margin. All three violators (2031, 2033 and 2035) occur due to the requirement for burns along the EMME trajectory to remain on a dual Mars flyby path as shown in Table 2. All three have correction maneuvers for the full stack greater than $500 \mathrm{~m} / \mathrm{s}$ and up to about $1000 \mathrm{~m} / \mathrm{s}$. All the other opportunities have around $200 \mathrm{~m} / \mathrm{s}$ or less including 3 opportunities $(2024,2039,2041)$ that require $0 \mathrm{~m} / \mathrm{s}$ en-route $\Delta v$. Thus, the propellant required to maintain an EMME trajectory is key to its success and the behavior appears cyclical. As a result, to take advantage of this phenomenon, the missions would need to be regulated to specific periods. The applicability to long term sustainability is thus challenged. However, for an early mission concept in the decade from 2020-2030 there is are several potential opportunities for 2 launch feasibility. If the focus on early missions to Mars is delayed, the opportunities commence again in the late 2030's. 
For the Full-Up Habitat architecture 8 out of the 9 cases (88.9\%) are feasible with an additional year (2033) with almost 0 payload mass margin as shown in Figure $7 \mathrm{c}$. In addition, the other years feature fully stacked masses, although the mass trade could move payload to the third flight in many of these epochs and margin could be restored. The feasibility of the Full-Up Habitat architecture compares favorably against the Dual Habitat architecture without the increased risk. Of course all habitats are sized for the transit leg only, so additional habitation mass to survive during the Mars stay would likely bump many of these opportunities into the 4 SLS launch strata. In addition the Full-Up Habitat architecture has reduced variability compared to the Dual Habitat or Loiter Habitat architectures. Examining Table 3 column by column makes these trends more apparent.

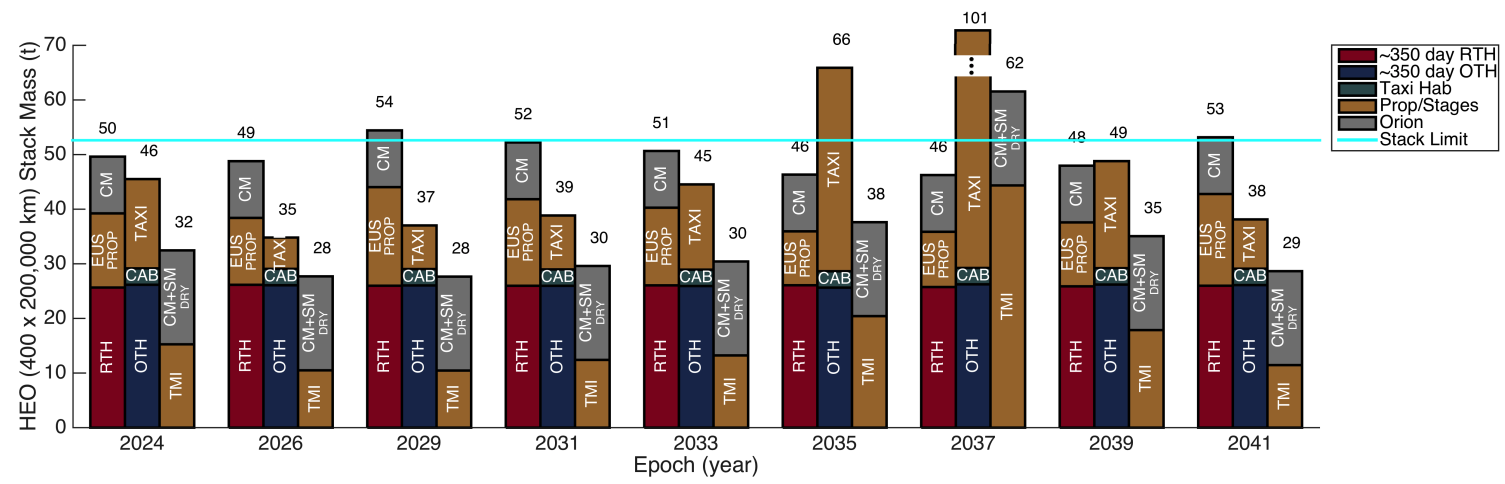

(a) Dual Hab 3 SLS Launch Feasibility

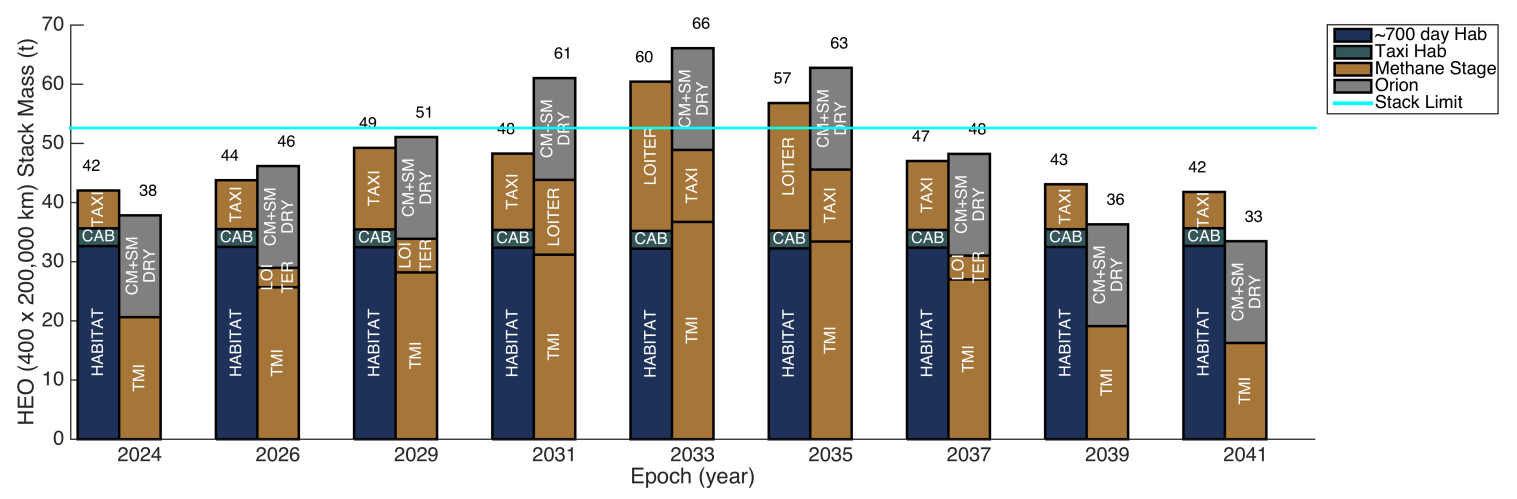

(b) Loiter Hab 2 SLS Launch Feasibility

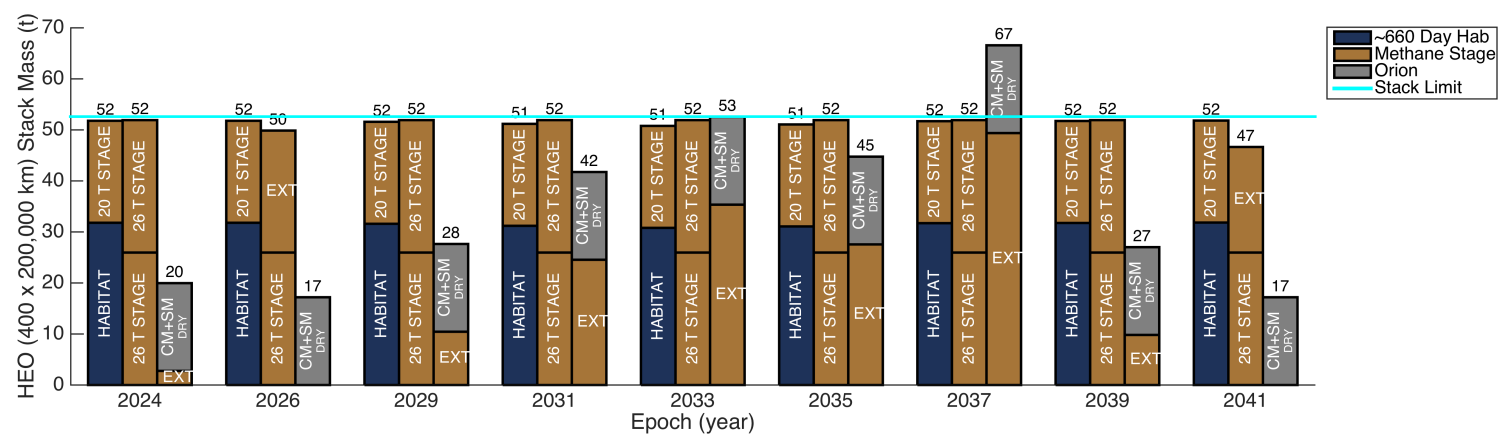

(c) Full Up Hab 3 SLS Launch Feasibility

Figure 7: Sizing Analysis for Mission Closure 
To make the comparison more distinct, Figure 8 was generated showing the total payload masses aggregated with stack limits for multiple launches displayed accordingly. Comparing Dual Habitat and Full-Up Habitat directly against each other confirms the revelation that the Full-Up option usually matches Dual Habitat in performance with Dual Habitat out performing Full-Up about half the time and vice versa. In contrast, the Loiter Habitat method clearly outperforms either architecture and frequently substantially so except in 2033. In addition, multiple opportunities exist with Loiter Habitat with significant margin against the two launch stack limit.

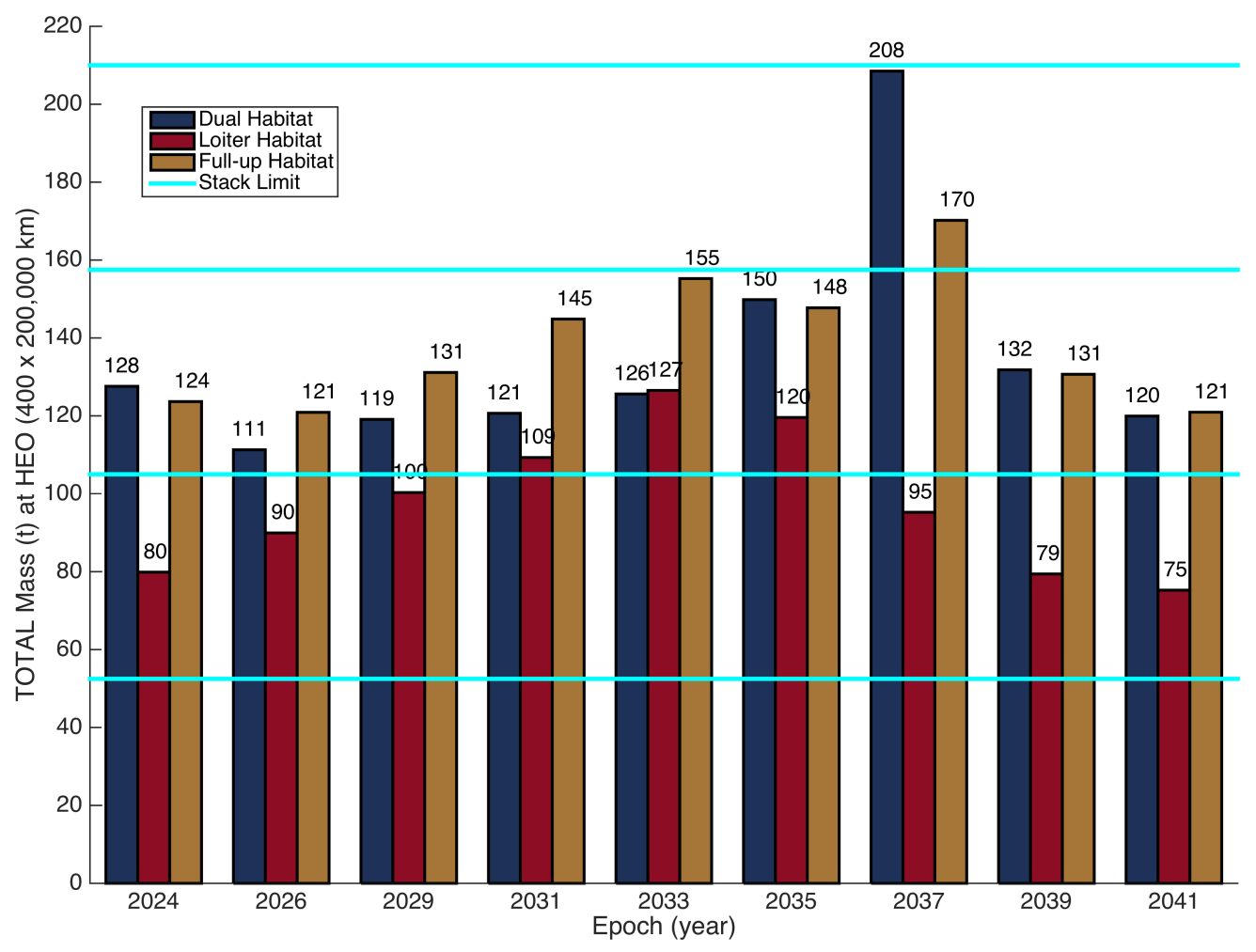

Figure 8: Total Mass to HEO Architecture Comparison

\section{Infusing Hyperbolic Trajectories into Any Mars Architecture}

The trajectories described and assessed to in this paper demonstrate a capability that minimizes mass delivered deep into the Mars gravity well. In the end, the exact architectural characteristics need not be adhered to precisely in order to take advantage of the phenomenon. To that end, a quick look at how to parameterize the benefits of applying the features of hyperbolic flyby trajectories is summarized.

The maneuvers can be generally divided into two categories, those that involve the large full stack or large mass $\Delta v^{\prime} s$ or small mass $\Delta v^{\prime} s$ that involve a smaller mass such as the Mars taxi vehicle. Figure 9 shows how these values are separated into large and small mass categories and their relative variation over the epoch scans. In general, as shown in the top half of Figure 9, the Full-Up Habitat $\Delta v$ requirements are the highest for large masses, followed by the Dual Habitat and the Loiter Habitat. However, the Loiter Habitat has a higher $\Delta v$ variation and can exceed the Dual Habitat values at times due to excessive in-route costs to maintain the EMME trajectory. These maneuvers involve moving around the habitats and in-space stages, upward of 50 metric tons. For the small mass values in the bottom half of Figure 9, the Full-Up costs are 0 while the Loiter Habitat averages the lowest costs compared to the the Dual Habitat which has large $\Delta v$ variability with only a few cases below Loiter Habitat capabilities. The small maneuvers most only push 
around the taxi cab which is generally in the 10-20 metric ton range.

Based on the results of Figure 9, applying average masses as $\Delta v$ multipliers to the small mass and large mass values results in Figure 10. Immediately what can be seen is a direct correlation with Figure 8. Thus, the challenge for Mars mission designers is to minimize the masses in each category as well as the total cost of the relative maneuvers. The relative launch costs would therefore be reduced accordingly. For example, if the taxi vehicle mass could be reduced the total on the pad mass for Loiter Habitat may dip below the minimum 2 launch threshold for all opportunities.
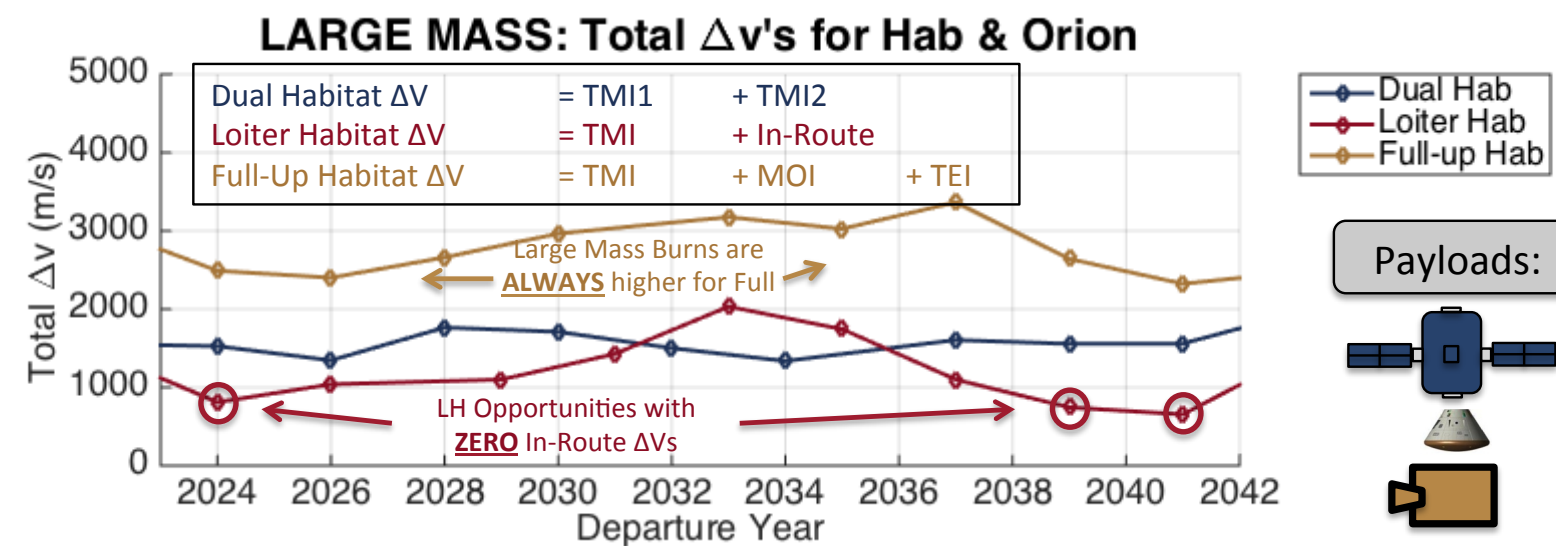

\section{SMALL MASS: Total $\Delta v$ 's for Taxi Hab}

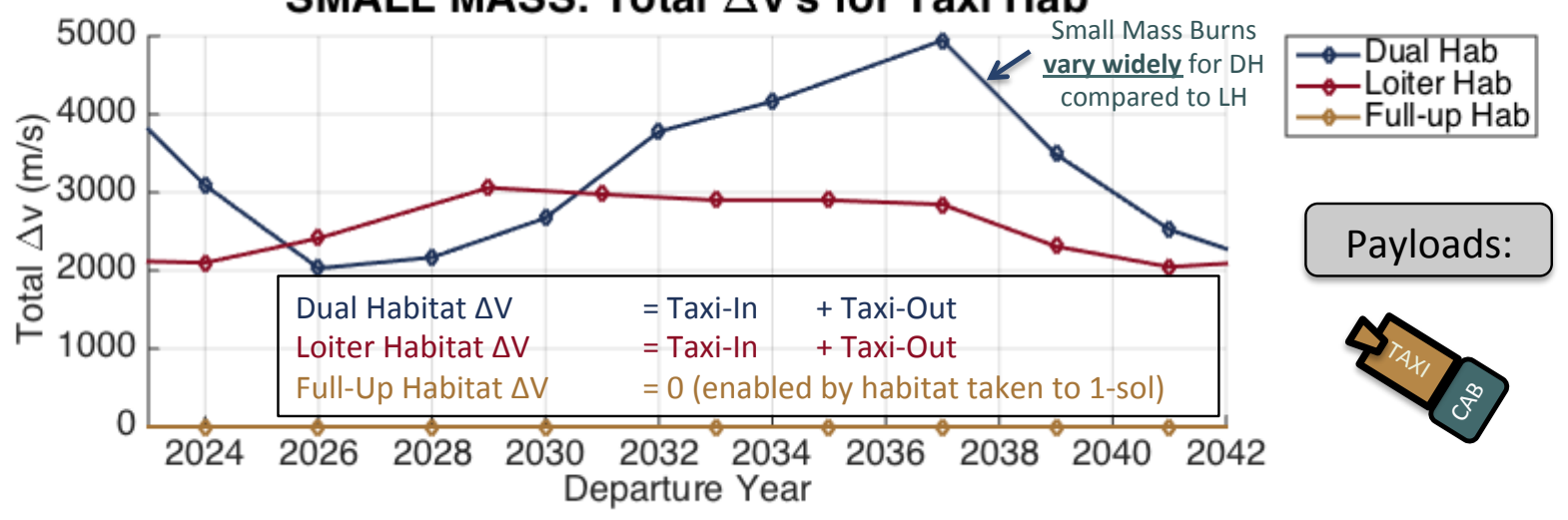

Figure 9: $\Delta v$ Values Divided by Mass Class

But even if a Loiter Habitat architecture is not pursued, Figures 9 and Figure 10 demonstrate the value of not bringing the full stack to Mars 1-sol. Thus it would be wise to invest more time understanding higher orbits for insertion, loosely captured around Mars. This may be the compromise that enables fewer launches with lowest risk and greatest return on investment. 


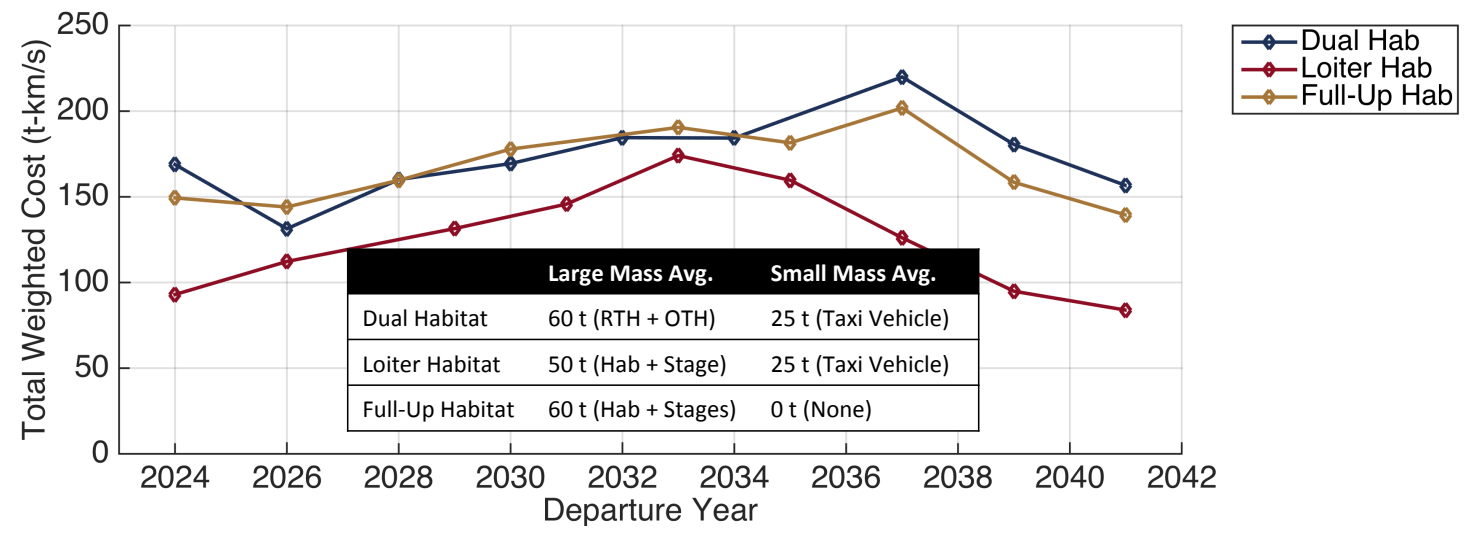

Figure 10: Weighted $\Delta v$ Values by Average Mass

\section{Conclusion}

Mars is hard. That has been a common theme in mission planning circles. The goal in this paper is to introduce and assess innovative ideas that makes Mars more accessible. Of the three proposed architectures, the Loiter Habitat architecture has the most promise, although not without caveats and risks such as opportunity variation and the ability to successful conduct hyperbolic rendezvous. In addition, forward work is necessary to understand the impact of using the Loiter Habitat framework to land on the surface of Mars. In the end it will come down to technology investment, but unique trajectories will be a key part of the future successful implementation of a stepwise approach to Mars. Using Mars free return trajectories and hyperbolic rendezvous will likely be contributing features that enable the journey.

\section{References}

${ }^{1}$ R. Zubrin, R. W. and Clarke, A. C., The Case for Mars, Free Press, ISBN - 068435509, 1996.

${ }^{2}$ International Space Exploration Coordination Group, "The Global Exploration Roadmap," August 2013.

${ }^{3}$ NASA, Report of the 90-Day Study on Human Exploration of the Moon and Mars, NASA-TM-102999, 1989.

${ }^{4}$ Council, N. R., Pathways to Exploration: Rationales and Approaches for a U.S. Program of Human Space Exploration, National Academies Press, 2014, Washington, D.C.

${ }^{5}$ Drake, B., Human Exploration of Mars Design Reference Architecture 5.0, NASA-SP-2009-566, 2009.

${ }^{6}$ H. Price, J. B. and Naderi, F., "A Minimal Architecture for Human Journeys to Mars," New Space, Jet Propulsion Laboratory, California Institute of Technology, June 2015, pp. 73-81, Pasadena, CA.

${ }^{7}$ Tito, D., "Feasibility Analysis for a Manned Mars Free-Return Mission in 2018," IEEE Aerospace Conference, Paper 978-1-4673-1813-6, March 2013, Big Sky, Montana.

${ }^{8}$ Craig, D., "The Evolvable Mars Campaign - Study Status," IEEE Aerospace Conference, ISBN 978-1-4799-5379-0, March 2015, Big Sky, Montana.

${ }^{9}$ Merrill, R., "Mars Conjunction Crewed Missions with a Reusable Hybrid Architecture," IEEE Aerospace Conference, ISBN 978-1-4799-5379-0, March 2015, Big Sky, Montana.

${ }^{10}$ Abercromby, A., "Human Exploration of Phobos," IEEE Aerospace Conference, ISBN 978-1-4799-5379-0, March 2015, Big Sky, Montana.

${ }^{11}$ Percy, T., "Combining Solar Electric Propulsion and Chemical Propulsion for Crewed Missions to Mars," IEEE Aerospace Conference, ISBN 978-1-4799-5379-0, March 2015, Big Sky, Montana.

${ }^{12}$ Landau, D. F. and Longuski, J. M., "Human Exploration of Mars via Earth-Mars Semicyclers," Journal of Spacecraft and Rockets, Vol. 44, No. 1, 2007, pp. 203-210.

${ }^{13}$ A. Thomas, C. Ocampo, D. L., "A Crewed Mars Exploration Architecture Using Flyby and Return Trajectories," 25th AAS/AIAA Space Flight Mechanics Meeting, AAS 15-372, January 2015, Williamsburg, VA.

${ }^{14}$ Landau, D. and Longuski, J., "Guidance Strategy for Hyperbolic Rendezvous," AIAA/AAS Astrodynamics Specialist Conference and Exhibit, AIAA 2008-7499, August 2009, Honolulu, HI.

${ }^{15}$ Jedrey, R., "Hyperbolic Rendezvous at Mars: Risk Assessments and Mitigation Strategies," AAS/AIAA Astrodynamics Specialist Conference, August 2015, AAS 15-753.

${ }^{16}$ NASA, Space Launch System (SLS) Program Mission Planner's Guide (MPG) Executive Overview, 2014, SLS-MNL-201.

${ }^{17}$ Ph.D., S. J. H. and Toups, L., "Deep Space Habitat Concept of Operations for Extended Duration Transit Missions," Global Space Exploration Conference, GLEX-2012.05.3.7x12291, May 2012. 
${ }^{18}$ Simon, M., Smitherman, D., and Toups, L., "Potential Applications of Modularity to Enable a Deep Space Habitation Capability for Future Human Exploration Beyond Low-Earth Orbit," Global Space Exploration Conference, GLEX2012.05.3.6x12574, May 2012.

${ }^{19}$ E. Hurlbert, T. Angstadt, M. Villemarette, J. Collins, J. Allred, J. Mahoney and T. Peters, "870 lbf Reaction Control System Tests using LOx/Ethanol and LOx/Methane at White Sands Test Facility," 44th AIAA/ASME/SAE/ASEE Joint Propulsion Conference and Exhibit, AIAA 2008-5247, July 2008, Hartford, CT.

${ }^{20}$ Rucker, M., "Design Considerations for a Mars Crewed Ascent Vehicle," AIAA Space 2015, August 2015, Pasadena, CA. 